\section{QUARTERLY REPORT}

Recaivad hy

OCT OO 1990

September 15, 1989 to December 14, 1989

DOE Grant No.: DE-FG22-87PC79907

\title{
SPECTROSCOPIC STUDY OF COAL STRUCTURE AND REACTIVITY
}

Report From:

Project Officer:
Peter R. Griffiths

Department of Chemistry

University of Idaho

Moscow, ID 83843

Principal Investigator:

Dallas L. Rabenstein

Department of Chemistry

University of California, Riverside

Riverside, CA.92521

Dr. Dennis Finseth, MS 94-101

Pittsburgh Energy Technology Center

U.S. Department of Energy

Pittsburgh, PA 15236

Signed:

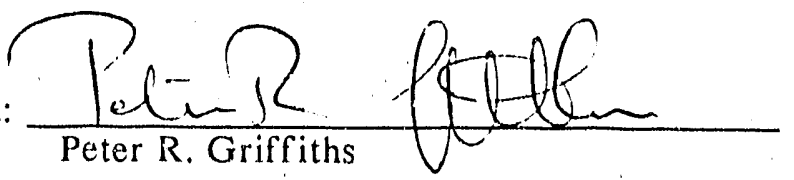

Date: $9-7-90$

\section{MASIER}




\section{Summary}

Work done during this period (September 15 and December 14, 1989) covered two of the three primary areas of study, of this project. The first concerned an investigation of the use of maximum likelihood restoration (MLR) as an alternative to Fourier self-deconvolution (FSD) for reducing the width of bands of complex spectral multiplets with many overlapping bands, of the type that are found in the infrared spectra of coals. The second involved the continuing development of" a step-scanning interferometer for the photoacoustic depth-profiling of materials whose composition varies in the spatial region between 5 and $50 \mu \mathrm{m}$ from its surface.

\section{Application of Maximum Likelihood Restoration to Complex Spectra}

The aim of this project is to perform quantitative analysis of the Fourier transform infrared (FT-IR) spectra of coals and coal extracts. The major difficulty encountered in the analysis of the FT-IR spectra of coals is the complexity of the bands, which vonsist of many closely overlapped peaks. Two techniques that are commonly used for the quantitative analysis of complex FT-IR spectra are deconvolution and curve-fitting. Deconvolution is a mathematical technique that narrows the peaks in a spectrum, thereby improving the effective resolution. Curve-fitting optimizes a set of band parameters, using a least squares criterion, to simulate the true spectrum. We have recently completed work on optimizing the combination of these two techniques with the aim of applying this to the spectra of coals and coal extracts. Two types of deconvolution were investigated in this context: Fourier self-deconvolution (FSD) and maximum likelihood restoration (MLR). It was concluded that for noisy spectra MLR gave superior results. This work is to be published in the near future [1-3].

In our earlier studies finely ground coal was extracted using chloroform. The FT-IR spectrum of the $\mathrm{C}-\mathrm{H}$ stretching region of a dilute solution of the extract in spectral grade carbon tetrachloride was then obtained. Figure 1 shows a typical example of such a spectrum, and the best deconvolution results that could be obtained using MLR. Although there are many more bands apparent after deconvolution there are probably othe bands which remain unresolved. Furthermore, it is possible that some of the smaller bands are artifacts from the deconvolution process. 
Since these problems stem from the extreme complexity of the FT-IR spectra of cual extracts our recent efforts have concentrated on analyzing spectra obtained by thin hayer chromatography coupled with diffuse reflectance FT-IR spectroscopy (TLC-DRIFTS). In this technique a strong solvent is used to transfer the eluites from the TLC plate to a series of cups filled with a powdercel IR transparent glass. This gives approximately 50 spectra from 1 extract. The sum of all these spectra is compared with the spectrum of the whole coal extract in Figure 2. It can be seen that the aromatic compounds have not been eluted during the TLC process. This is indicated by the absence of intensity in the aromatic $(\mathrm{C}-\mathrm{H})$ stretching region $\left(3100\right.$ to $\left.3000 \mathrm{~cm}^{-1}\right)$ and in the aromatic $(\mathrm{C}-\mathrm{II})$ bending region (930 to $680 \mathrm{~cm}^{-1}$ ). The simplification of the spectra obtained using this technique should greatly facilitate the analysis.

Figure 3 shows a series of spectra from different cups. Although there are no obvious bands that are only present in some spectra, significant intensity changes in relative band intensities can be seen. This is particularly apparent in the $\mathrm{C}=\mathrm{O}$ stretching region $\left(1790\right.$ to $\left.1680 \mathrm{~cm}^{-1}\right)$ and in the $\mathrm{C}-\mathrm{O}$ stretching region $\left(1260\right.$ to $\left.1100 \mathrm{~cm}^{-1}\right)$. These are two of the main regions for studies of coal oxidation using FT-IR.

Figure 4 shows the deconvolution of one of these spectra (cup \#38) in the region 1800 to 1000 $\mathrm{cm}^{-1}$ using both FSD and MLR. It can be seen that the spectrum deconvolved using MLR show's significantly better resolution, and also shows suppression of oscillations in the baseline region that are caused by noise. This confirms our earlier conclusions that MLR is better than FSD for the deconvolution of noisy spectra.

The same series of spectra that are shown in Figure 3 were deconvolved using MLR and are shown in Figure $\bar{\Sigma}$. After resolution enhancement several more bands become apparent, for example in the $\mathrm{C}=\mathrm{O}$ stretching region and in the $\mathrm{C}-\mathrm{O}$ stretching region. It should be noted, however, that the positions of the bruad bands between approximately 1270 and $1140 \mathrm{~cm}^{-1}$ are currently not very' reproducible and more work needs to be done in this area.

Current work is concentrating on the curve-fitting some of these deconvolved spectra, with the aim of testing the reproducibility of the results and to determine any systematic trends in the data. 


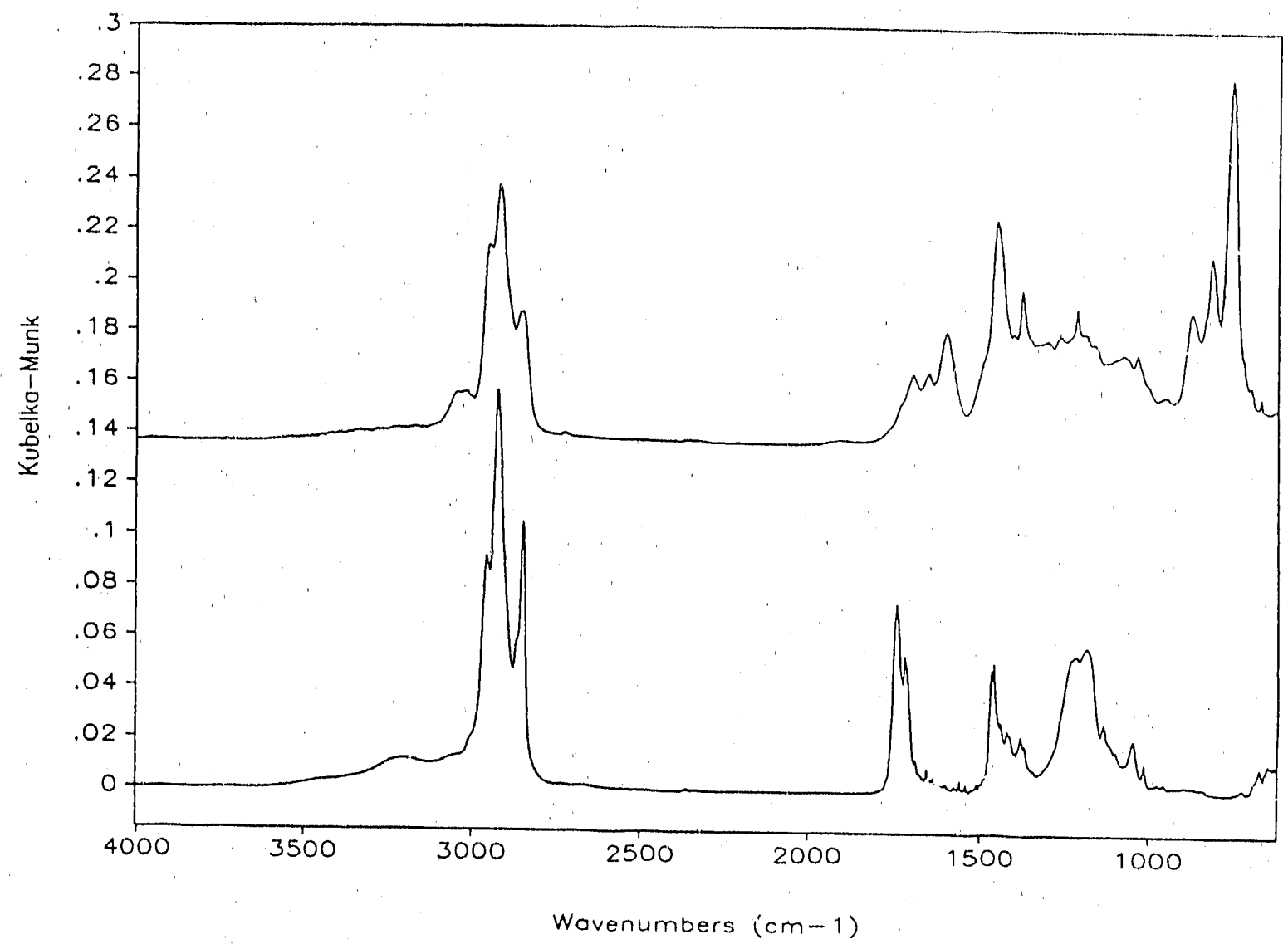

Figure 2. Comparison of a whole coal extract spectruin (top) and the sum of the 50 spectra obtained from the same extract using TLC-DRIFTS (bottom). 


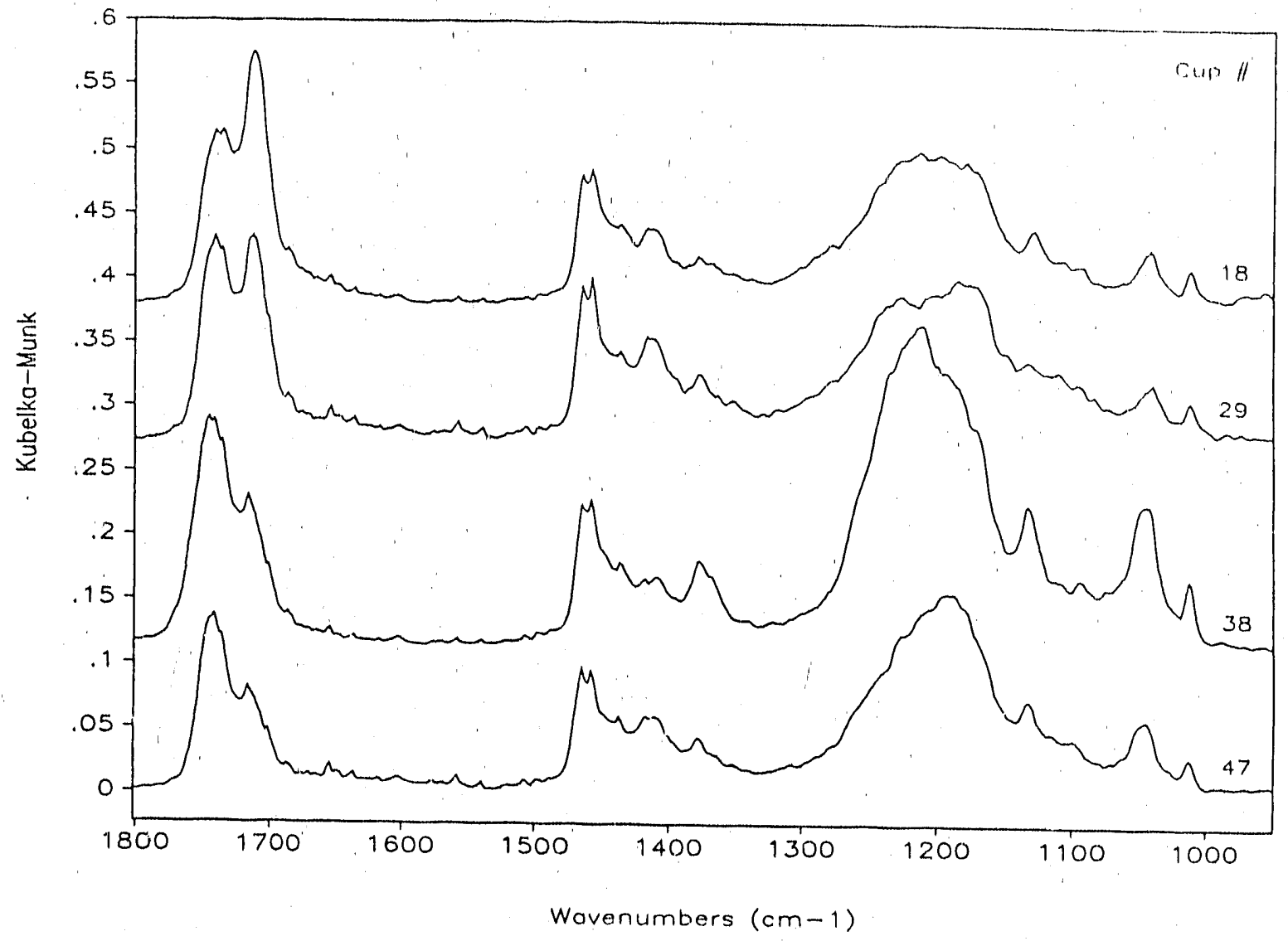

Figure 3. Represcntative members of a series of 50 spectra obtained from a coal extract using TLCDRIFTS. 


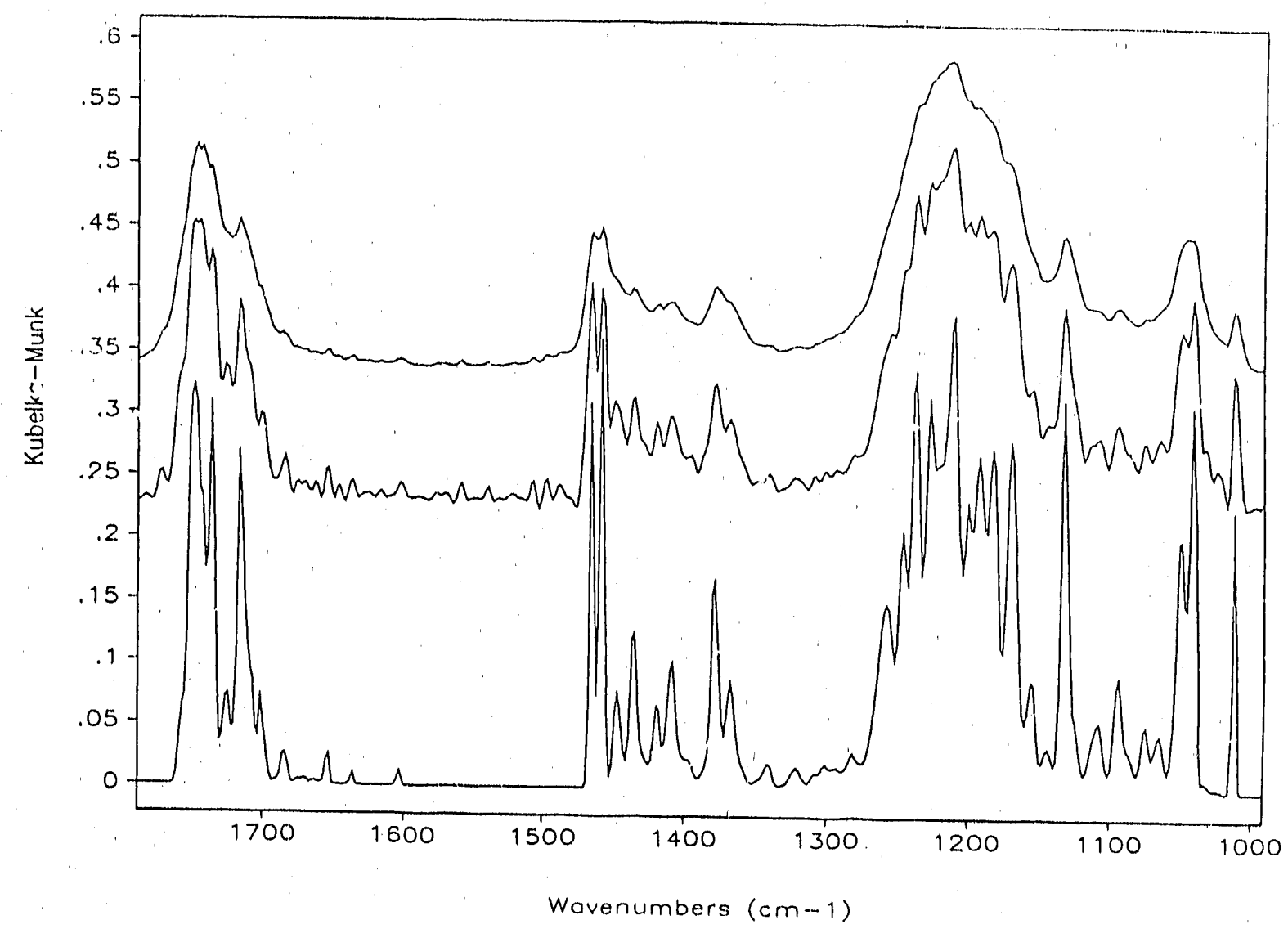

Figure 4. One of a series (cup \#38) of 50 spectra obtained from a coal extract using TLC-DRIFTS. Top: original spectrum. Middle: spectrum after application of FSD. Bottom: spectrum after application of MLR. 


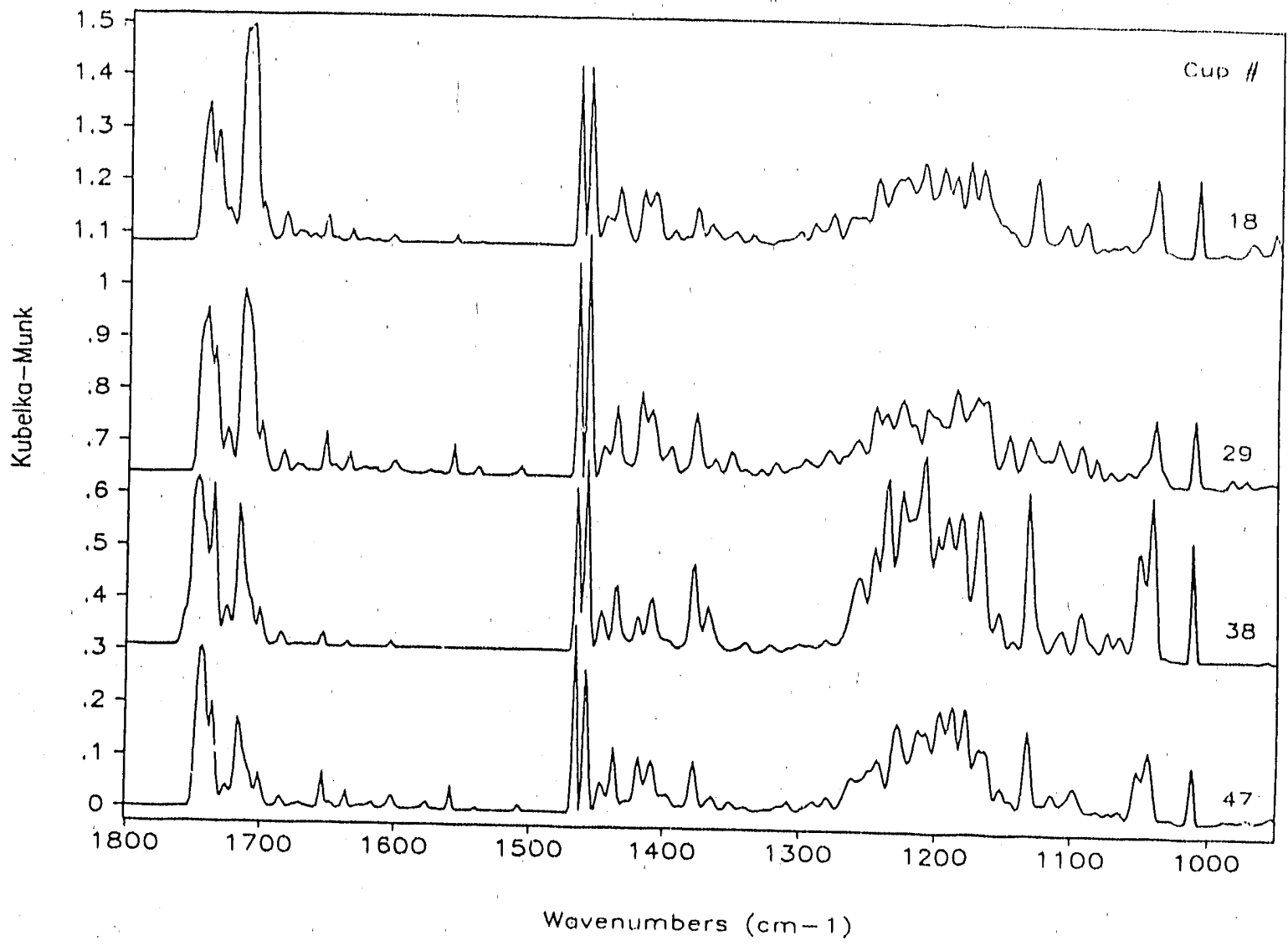

Figure 5. The same series of spectra as shown in Figure 3, after application of MLR. 


\section{Step-Scanning Interferometer}

The step-scanning interferometer that was constructed in our laboratory during the first two years of this project incorporated a mechanical stepper-motor drive. It is known that for stepscanning interferometry, the distance between each sampling position must be identical, and any deviation will lead to a decrease in signal-to-noise ratio (SNR). We have shown that for photoacoustic depth-profiling with a step-scanning interferometer the positioning error should be less than $5 \mathrm{~nm}$. The accuracy at which the movable mirror could be positioned using the steppermotor drive alone is insufficient to allow this specification to be met. By using the laser reference interference record to monitor positional inaccuracy, the mirror position error could be corrected using a piezoelectric transducer (PZT) as a fine control of the mirror position.

Briefly, the PZT control circuit works as follows. The computer acquires the He-Ne laser interference record which is recorded with a d.c. amplifier (in contrast to the case for a rapidscanning interferometer). For a rapid--scanning interferometer, this point is called the laser zerocrossing (LZC), but because the interference record is measured at d.c., the entire interference record is positive and the LZC is not at zero. Nevertheless, this point is still termed the LZC in this work; it gives the most sensitive measure of the position of the movable interferometer mirror. The computer then sets up a digital-to-analog converter (DAC) in the control circuit. Two comparators monitor whether the analog laser voltage is greater or less than upper and lower control limits set just above and below the LZC value. The outputs of the comparators are fed into an integrator whose output is sent to the high-voltage amplifier that controls the fine-control PZT element. If the retardation is too small, the laser voltage is too high and the comparator outputs cause the integrator voltage to increase, thus increasing the thickness of the PZT and causing the retardation to increase. The converse operation occurs when the optical retardation is too large.

Although this system allowed good results to be obtained, it still gave rise to several problems:

a. The time required to move from one sampling position to the next was very long, resulting in an excessively long measurement time;

b. It was not possible to operate the spectrometer in the rapid-scanning mode making optical alignment difficult;

c. The moving mirror could not be returned to the same starting position for successive scans 
because of hysteresis.

We believed that these problems could be alleviated by substituting the stepper-motor cirive by an unusual piezoelectric drive that allows a travel of greater than $4 \mathrm{~mm}$ ("Inchworm", Burleigh Instruments), Figure 6 shows the manner in which the Inchworm operates. There are linree piezoelectric elements ( 2 clamps and 1 extension bar). The extension bar starts at its minimum length and the forward clamp is clamped to the drive spindle. As extension bar (which is fixed to the bench at its mid-point) expands, thus moving the spindle forward. Each step nominally corresponds to an expansion of $4 \mathrm{~nm}$. When 256 steps have been made, the extension bar is at its maximum length. At this point, the forward clamps unclamps and the rear clamp clamps. This series of steps is known as the clamping cycle. Further command steps cause the extension element to shrink, thus pulling the spindle forward. After 256 steps, the clamps are switched again and the Inchworm motor has come full cycle. Operation of the Inchworm motion is very fast, with the highest translation speed being about $0.5 \mathrm{~mm} / \mathrm{s}$. Operation of the step-scanning interferometer at this speed would be equivalent to a conventional rapid-scanning interferometer operating at slow speed $(1.58 \mathrm{kHz}$ for the laser interferogram) and would enable optical alignment to be easily carried out. In addition, the movable mirror can be advanced much more rapidly between successive sampling positions than it could with the stepper-motor control, simply by calling the Inchworm to advance a specified number of steps, $n$. Finally, the movable mirror should be able to return to the same starting position for successive scans; if the previous interferogram was measured at $N$ sampling positions, the movable mirror should be returned to its starting position simply by specifying that it returns $n N$ steps. Thus we believed that the installation of an Inchworm drive would enable all three disadvantages of the stepper-motor drive listed above to be overcome.

Schematics for installing the new drive were drawn up and the control programs were written during the first eight weeks of this quarter. The drive was installed in November. Unfortunately, two problems with the Inchworn were encountered that we were unaware of when the drive was purchased. The first problem is that during the clamping cycle the spindle is loose momentarily. The He-Ne reference laser interference record shows this by deviating from its normal sine wave form into a large "glitch" that can last on the order of up to about $25 \mathrm{~ms}$. The second problem is that the step size for the Inchworm motor, that is specified as being $4 \mathrm{~nm}$ by the manufacturer, actually 


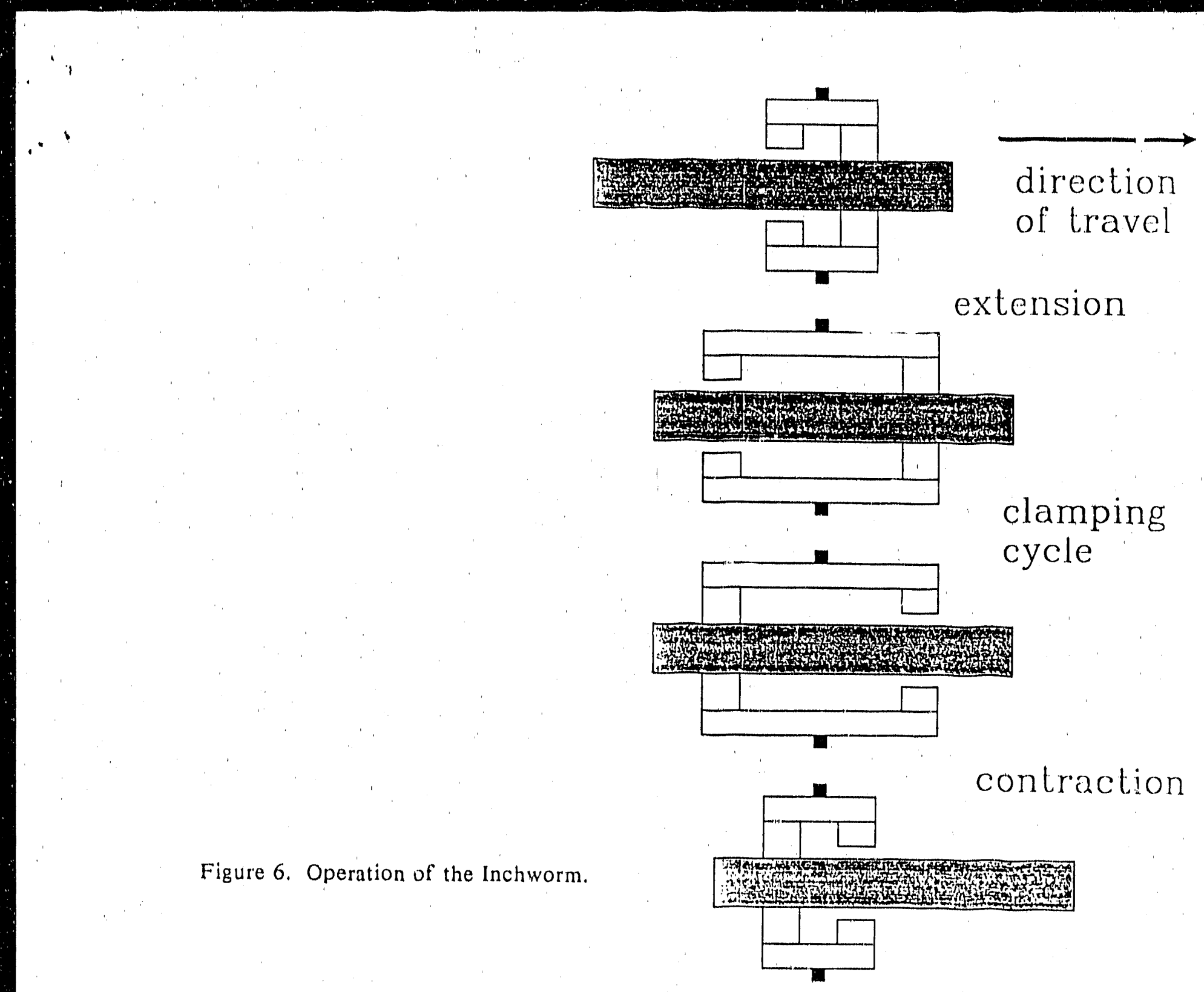


varies during the expansion and contraction portions of the stepping cycle. The numbor of steps required to move one laser fringe is shown in the histogram in Figure 7; it can be seen that the required number of steps sizes of 3.4 to $8.0 \mathrm{~nm}$, with a inean of $5.7 \mathrm{~nm}$.

These two problems made control of the stepping motion required for the interferometer difficult. It had been hoped that the Inchworm's step size would be constant at about $4 \mathrm{~nm}$ (as is implied in the manufacturer's promotional literature). This would have allowed the instruments computer to calculate exactly how many steps are needed to reach the next sampling position and the Inchworm could be driven forward by that many steps at high speed. Methods of circumventing the effect of these problems were devised and their implementation will be described in the next quarterly report.

\section{$\underline{\text { References }}$}

1. Richard S. Jackson, Peter R. Griffiths, John A. Pierce and Gao Hongjin in "Proceedings of the $7^{\text {th }}$ Internatiunal Conference on Fourier Transform Spectroscopy". To be published, SPIE, Washington, DC.

2. John A. Pierce, Richard S. Jackson, Kenneth W. Van Every, Peter R. Griffiths and Gao Hongjin Anal. Chem., 62, 477 (1990).

3. "A Comparison of Maximum Likelihood Restoration and Fourier Self Deconvolution for Combined deconvolution and Curve-fitting". In preparation.

\section{DISCLAIMER}

\footnotetext{
This report was prepared as an account of work sponsored by an agency of the United States Government. Neither the United States Government nor any agency thereof, nor any of their bility for the accuracy, completeness, or implied, or assumes any legal liability or responsiprocess disclosed, or represents that, or usefulness of any information, apparatus, product, or ence herein to any specific commercial product, not infringe privately owned tights. Refermanufacturer, or otherwise does not neceduct, process, or service by trade name, trademark, mendation, or favoring by the United States Gonstitute or imply its cridorsement, recom. and opinions of authors expressed herein do not nentent or any agency thereof. The views United States Government or any agency theres.
} 
$\therefore$
$\therefore$

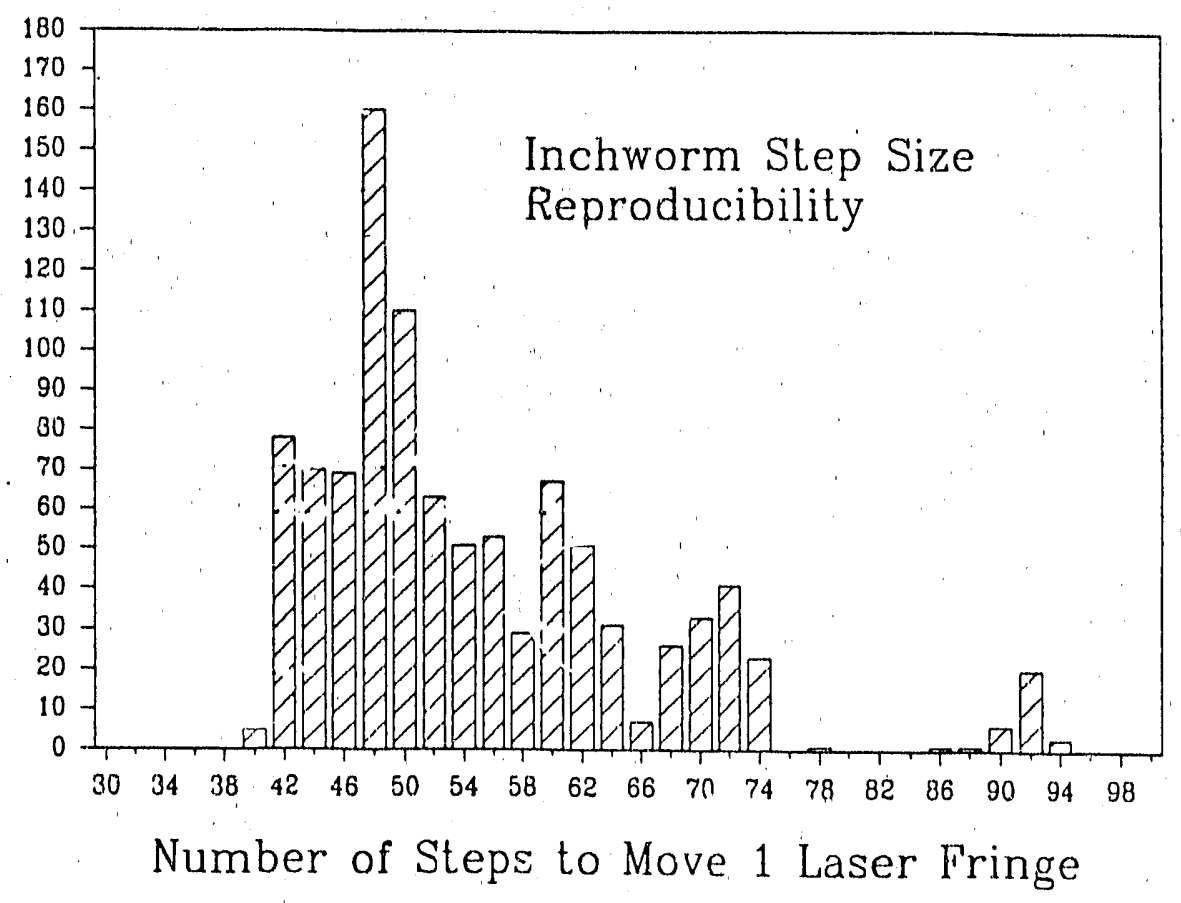

Figure 7. Histogra' $n$ showing the number of steps of the Inchworm to translate the moving mirror by one laser fringe $(0.6328 \mu \mathrm{m}$ retal dation). 

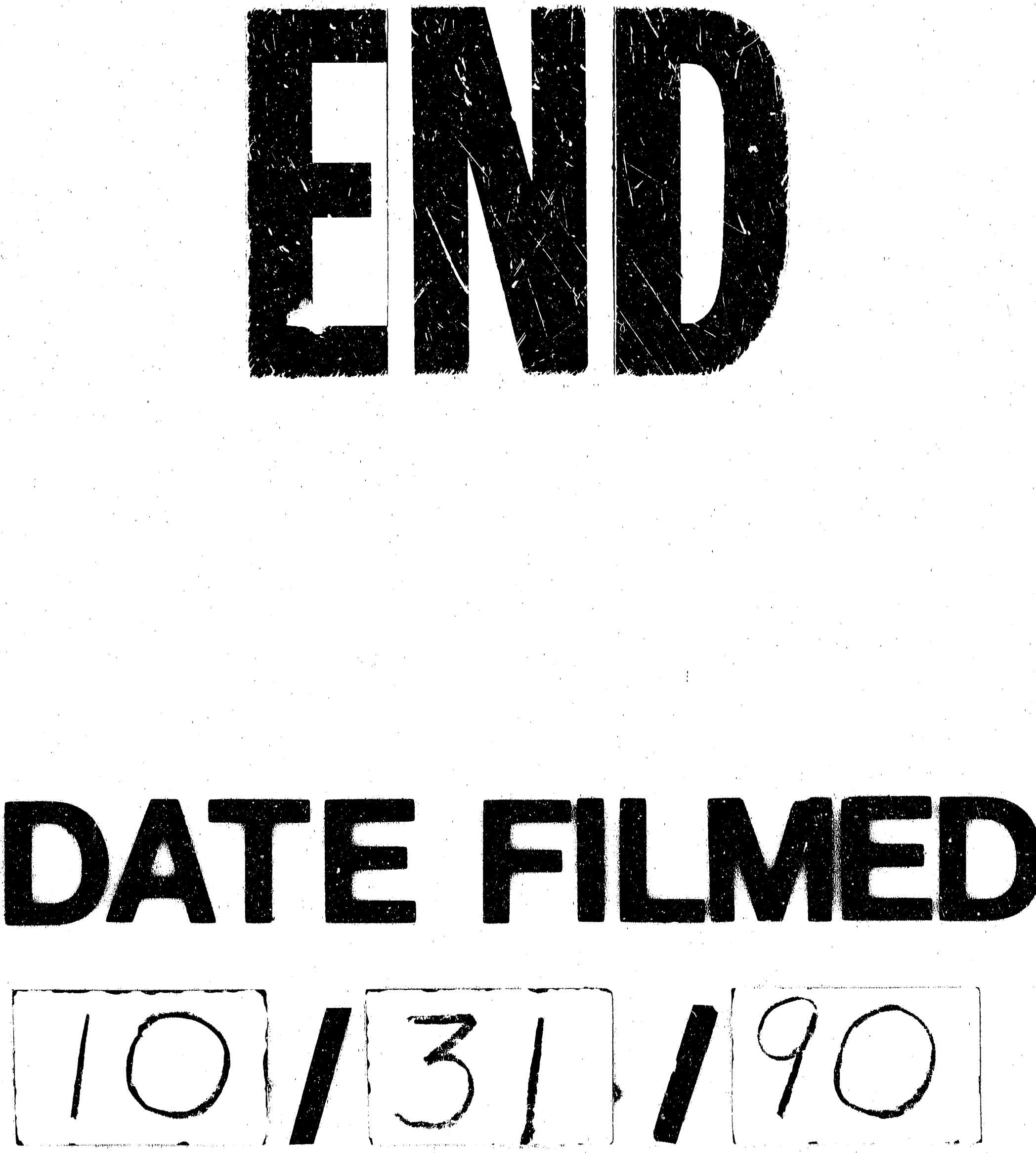
